\title{
Assessment of the quality of childcare centres in the Colombo Municipal Council area
}

\author{
H M D Herath ${ }^{1}$, P M G Punchihewa ${ }^{2}$, H M Bhagya Herath ${ }^{3}$, H M Madhavie Herath ${ }^{4}$
}

Sri Lanka Journal of Child Health, 2013; 42: 200-204

\begin{abstract}
Background: There are 2 dimensions of childcare quality: process and structure. The interactions, activities, materials, learning opportunities, health and safety routines refer to process quality. Structural quality includes the group size, adultchild ratio and professional training of staff. No large scale studies are available on the quality of Sri Lankan childcare centres.
\end{abstract}

Objectives: To assess the quality of preschool and day care centres in the Colombo Municipal Council $(\mathrm{CMC})$ area and to evaluate how structural inputs and cost influence the process quality.

Design: Descriptive cross-sectional qualitative study

Method: Process quality was assessed using the Early Childhood Environmental Rating ScaleRevised. The cost and structural quality was assessed using a self-administered questionnaire.

Results: Overall process quality was mediocre, with $25 \%$ preschools being of poor quality and $6 \%$ being of good quality. Over half the centres did not have appropriate number of staff. Eighty percent of child groups were larger than appropriate. Only $8 \%$ of centres were led by a graduate. Of the teachers, $90 \%$ had preschool teacher training. Smaller student groups cared for by a higher number of staff had significantly higher process quality. Better quality preschools cost more.

Conclusions: The quality of care provided by childcare centres in the 6 Medical Officer of Health areas of $\mathrm{CMC}$ area was mediocre.

(Key words: Child care centre; quality; preschools; Montessori; day care centre; Colombo)

\section{Background}

Basic principles of neuroscience indicate that providing supportive conditions for early childhood

${ }^{1}$ Senior Registrar, ${ }^{2}$ Consultant paediatrician, Lady Ridgeway Hospital, Colombo, ${ }^{3}$ Attorney at Law, ${ }^{4}$ Sociologist

(Received on 19 April 2013: Accepted after revision on 21 June 2013) development is more effective and less costly than later addressing consequences of early adversity. A balanced approach to emotional, social, cognitive and language development leads to better cognitive and social skills in the school years and beyond ${ }^{1,2}$. Poor quality childcare experiences are associated with behavioural problems. Only good to excellent quality pre-schools, often defined as scoring 5 or above on Early Childhood Environmental Rating Scale-Revised (ECERS-R) ${ }^{3}$, are known to produce better outcomes.

Increasing numbers of Sri Lankan children attend 2 types of childcare centres: morning programmes known as preschools /Montessori and day care centres which continue from morning to evening. Their quality is an important determinant of the development of children in care. Therefore, it is important to evaluate the level of care in Sri Lankan childcare centres.

There are various observational tools to evaluate process quality such as ECERS-R and Classroom Assessment Scoring System ${ }^{\mathrm{TM}}\left(\mathrm{CLASS}^{\mathrm{TM}}\right)^{4}$. Of these, ECERS-R is a widely used and validated rating scale, routinely used by UK and $\mathrm{USA}^{3}$.

The preschool statute that came into operation in 2005, stipulated 10 mandatory basic and minimum standards viz. allocation of minimum building space of 10 sq. feet per child, preparation of toilet network for every 25 children, allocation of doors and windows to $1 / 7^{\text {th }}$ of floor area, possession of a protective wall or fence and a courtyard for sports, maintenance of a first aid box and sport facilities as ordered by the advisory committee, allocation of one teacher for each 20 children, possession of adequate furniture, equipment and premises for observance of religious rites. Registration with a local authority is a legal requirement.

No large scale or nationally representative studies using standardised observational tools to evaluate childcare quality have been carried out in Sri Lanka.

\section{Objectives}

- The primary objective is to assess the quality of care provided by childcare centres in the 6 Medical Officer of Health (MOH) areas of Colombo Municipal Council (CMC) area. 
- Specific objectives include assessing process quality using ECERS-R, assessing structural quality of the same centres, assessing the knowledge of teachers on child abuse, acceptable methods of discipline and first aid, evaluating the relationship between structural inputs and the process quality and looking at the relationship between the quality of care and the cost involved

\section{Method}

A descriptive cross-sectional study was carried out in all $6 \mathrm{MOH}$ areas of the CMC from December 2012 to March 2013. One hundred and ninety three centres caring for children between 2-6 years were identified based on information gathered from the office to implement preschool statute and public health inspectors. Ninety six centres were randomly selected for the study. Sample size was calculated using the method of S.K. Luwanga and S Lemeshow ${ }^{5}$ with a confidence interval of $90 \%$. The orphanages and specialised centres meant for disabled children were excluded. Written informed consent was obtained from the managers of the childcare centres prior to the study. Managers of six centres selected did not consent and six other centres were randomly allocated. Nobody withdrew consent after participation. Strict anonymity and confidentiality were maintained. Ethical clearance was obtained from the Ethical Review Committee of the Sri Lanka College of Paediatricians.

Structural aspects were assessed using a selfadministered questionnaire given to the managers. Where needed, explanation and help were given by researchers to fill in the questionnaire. The standards were as follows: maximum child group size to be at or below 16, child: staff ratio to be at or below $8: 1$, head teacher to have a BA degree in development or related field and majority of teachers to have preschool training for 12 months. Above thresholds were based on standards recommended by the National Resource Centre for Health and Safety in Child Care (USA), formulated in 1997. Statistically determined version of these standards was named Stepping Stones to Using Caring for Our Children. Many studies recommend similar standards in order to achieve individualised, warm and sensitive caregiver interactions $s^{6,7,8}$.

Following characteristics of the study population were collected using the same questionnaire: located $\mathrm{MOH}$ area, type of centre (Montessori only/ Montessori and day care), total number of children, total number of staff, number of children with special needs, registration status, funding status (private or funded by local authority/ charity) and monthly cost per student. The questionnaire was pretested in a centre outside the study area.
Process quality assessment consisted of observation of each centre for 1-2 hours using ECERS-R which includes 43 process quality items categorised into the following subscales: space and furnishings, personal care routines, language-reasoning, interactions, activities, programme structure, parents and staff. Each item has detailed descriptors that can be rated from 1-7, with (1) inadequate, (3) minimal, (5) good, and (7) excellent.

Investigators obtained a practical training on use of ECERS-R, in the form of a video guide published by the original authors. Each of the 43 items was independently rated in a model ECCD centre outside the study area. Each item was compared between three investigators that revealed a correlation of 0.7-0.8.

Ninety six staff members were given a multiple choice questionnaire on child abuse, methods of discipline and first aid. Data were analysed using SPSS mode. The significance was found using the Chi-square test.

\section{Results}

Ninety six childcare centres were randomly selected for the study. The total number of classrooms was 177 . The total number of children was 3788 and the total number of staff 311 .

The characteristics of the study population are shown in Table 1.

Table 1: Characteristics of study population

\begin{tabular}{|l|c|}
\hline \multicolumn{1}{|c|}{ Variable } & Number \\
\hline Mean age of children (months) & $48.3($ SD 8.0$)$ \\
\hline Type of centre & $82(85.4 \%)$ \\
Montessori only & $14(14.6 \%)$ \\
Montessori and day care & $19(19.7 \%)$ \\
\hline Children with special needs & $77(80.2 \%)$ \\
Allowed & \\
Not allowed & \\
\hline Registration status & $85(88.5 \%)$ \\
Registered with a governmental & $11(11.5 \%)$ \\
authority & \\
Not registered with any & \\
authority & $69(71.9 \%)$ \\
\hline Funding status & $14(14.6 \%)$ \\
Profit making centre & $13(13.5 \%)$ \\
Funded by a charity service & \\
Funded by local authority & $29(30.2 \%)$ \\
\hline Cost per student for a month & $45(46.9 \%)$ \\
< Rs. 500 & $22(22.9 \%)$ \\
\hline Rs. 501-1500 &
\end{tabular}

The distribution of quality across sub-scales is shown in Table 2. 
Table 2: Distribution of quality across sub-scales

\begin{tabular}{|l|ll|}
\hline ECERS subscale & Mean & SD \\
\hline Total score & 3.58 & 0.81 \\
\hline Space and furnishing & 3.56 & 1.10 \\
\hline Personal care routines & 3.90 & 1.01 \\
\hline Language reasoning & 3.93 & 0.68 \\
\hline Activities & 3.20 & 0.93 \\
\hline Interactions & 4.33 & 1.05 \\
\hline Program structure & 2.72 & 0.91 \\
\hline Parents and staff & 3.45 & 1.10 \\
\hline
\end{tabular}

The distribution of total mean score among centres is shown in Figure 1.

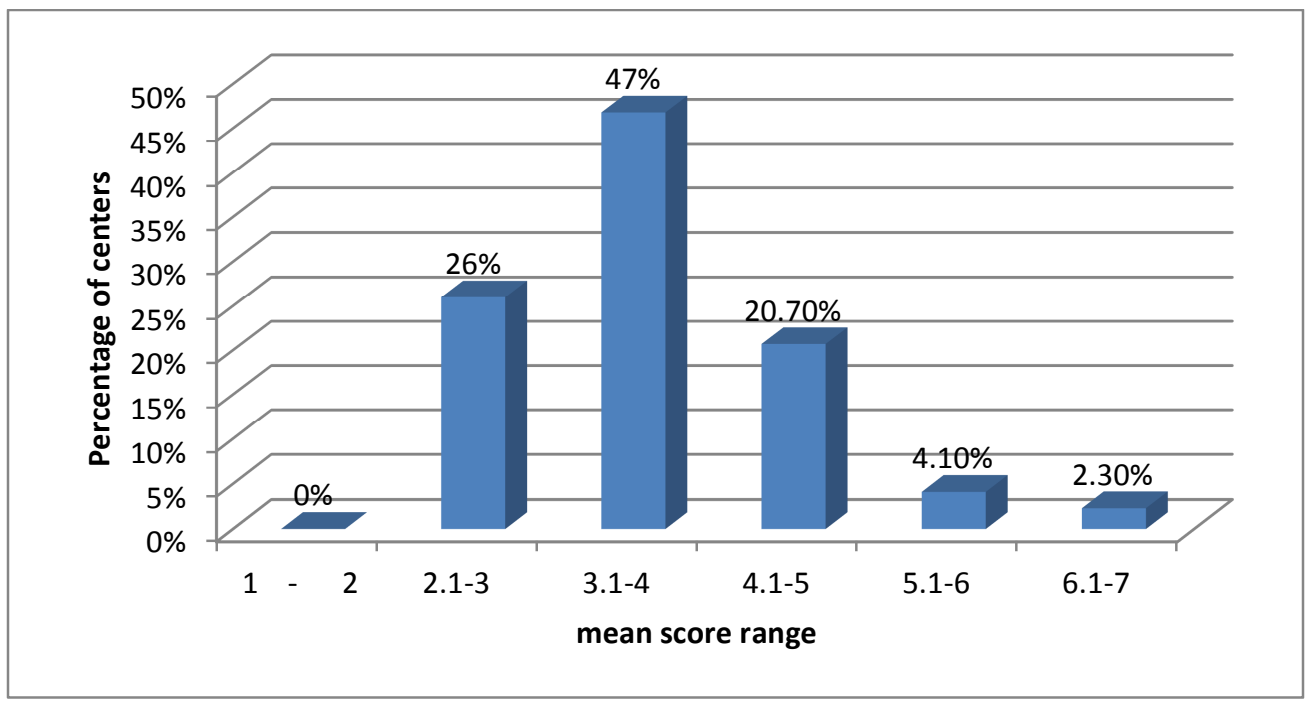

Figure 1: Distribution of total mean score among centres

Only $6.4 \%$ of programmes reached the ECERS 'good' benchmark of 5 and above. The great majority of programmes had scores of 3-4 (47\%), or $4-5(20 \%)$, which is less than the desired professional standard. Twenty six percent of programmes were of poor quality.
Percentage of centres with good, average and poor quality across sub-scales of ECERS-R is shown in Table 3 .

Table 3: Percentage of centres with good, average and poor quality across sub-scales of ECERS-R

\begin{tabular}{|l|c|c|c|}
\hline \multicolumn{1}{|c|}{ Sub scale } & Good quality & Average quality & Poor quality \\
\hline Total score & $6(6.3 \%)$ & $65(67.7 \%)$ & $25(26.0 \%)$ \\
\hline Space and furnishing & $13(13.5 \%)$ & $47(49.0 \%)$ & $36(37.5 \%)$ \\
\hline Personal care routines & $15(15.6 \%)$ & $58(60.4 \%)$ & $23(24.0 \%)$ \\
\hline Language reasoning & $12(12.5 \%)$ & $79(82.3 \%)$ & $5(5.2 \%)$ \\
\hline Activities & $6(6.3 \%)$ & $59(61.4 \%)$ & $31(32.3 \%)$ \\
\hline Interactions & $31(32.3 \%)$ & $56(58.3 \%)$ & $9(9.4 \%)$ \\
\hline Program structure & $2(2.1 \%)$ & $23(24.0 \%)$ & $71(74.0 \%)$ \\
\hline Parents and staff & $36(37.5 \%)$ & $48(50.0 \%)$ & $12(12.5 \%)$ \\
\hline
\end{tabular}

The process quality (mean 3.56, SD 0.81) across all subscales was below the desired level of 5.0. Among the subscales in ECERS-R, the programme structure scored lowest, showing poor quality in $74 \%$ of centres. These centres had too rigid, teacher-centred teaching schedules that had little opportunities for free play or child initiated activities.

Percentage of centres with satisfactory and unsatisfactory structural quality is shown in Table 4. 
Table 4: Percentage of centres with satisfactory and unsatisfactory structural quality

\begin{tabular}{|l|c|c|}
\hline \multicolumn{1}{|c|}{ Structural measure } & Satisfactory & Unsatisfactory \\
\hline Maximum group size of 16 & $19(19.8 \%)$ & $77(80.2 \%)$ \\
\hline Child :staff ratio of 8:1 & $41(42.7 \%)$ & $55(57.3 \%)$ \\
\hline Manager/Head teacher has a BA degree & $08(08.3 \%)$ & $88(91.7 \%)$ \\
\hline Majority of teachers have ECCD training >1year & $86(89.6 \%)$ & $10(10.4 \%)$ \\
\hline
\end{tabular}

The group size and child: staff ratio (C:S ratio) were below expected standards in $80.2 \%$, and $57.3 \%$ of centres respectively, even though they may have complied with the 20:1 ratio recommended by the preschool statute. Quality was significantly higher in preschools with desired $\mathrm{C}: \mathrm{S}$ ratio $\left(X^{2}=13.028, d f-1, p<0.001\right)$

The provider qualification shown to be associated with good quality care is a BA degree ${ }^{2}$. Only $8.3 \%$ of centres met this criterion. This number was too small for comparison with quality or the cost involved. Ninety percent of centres had teachers with preschool training, which is the recommendation of preschool statute, but this was not associated with better quality care $\left(\mathrm{X}^{2}=3.047\right.$, df-2, p 0.218)

Preschools with monthly cost of Rs. 500.001500.00 and $>1500.00$ provided better quality care $\left(X^{2}=7.92, d f=2, p 0.019\right)$. Sixty five percent of teachers scored $50 \%$ or above marks in the multiple choice questions on child abuse, methods of discipline and first aid.

\section{Discussion}

In our study, the process quality (mean 3.56, SD 0.81 ) across all subscales was below the desired level of 5.0. Many studies in developed countries using ECERS too revealed mean score below 5, even though in most studies at least a quarter of centres met the good total mean ECERS benchmark of $5^{9,10,11}$.

The Cost, Quality, and Outcomes Study (CQQ study-first phase -1995$)^{9}$ examined four hundred full-day child-care centres in four states of USA. Total mean ECERS score was 4.26 , with $76 \%$ of centres being of poor or mediocre quality. In our study, $94 \%$ of centres were rated poor or mediocre. CQQ Study was a large scale one which examined the positive influence of good quality centre-based child care on children's development during their preschool years and into primary education.

The Head Start Family and Child Experiences Survey (FACES) of USA examined classroom quality of 524 classrooms in Autumn 1997 and Autumn 1998, looking at structure (Child: staff ratio, class sizes, teacher experience), and classroom process. Process quality was assessed using four rating scale including ECERS. The mean
ECERS score for Autumn 1997 was 4.93 (SD 0.63 ). However, $72.4 \%$ of classrooms were of good quality as opposed to $6 \%$ in our study ${ }^{10}$. FACES is an on- going large scale study (19972013) which provides descriptive information on the characteristics, experiences and outcomes of Head Start children and families.

The Massachusetts Cost and Quality Study examined 90 community-based preschool programmes and 95 school-based, publiclyadministered preschool classrooms. The quality of early child care and education, the costs involved, the relationship between quality and costs and relationship between the family income and the quality of care were examined. The mean total score was 4.94 , with $70 \%$ centres meeting good quality ${ }^{11}$.

Our findings highlighted that regulatable classroom characteristics, such as child-staff ratio, can be significantly related to quality of early care and education. This study also highlighted the importance of being guided by research evidence to set thresholds for structural aspects of preschools.

\section{Conclusions}

- The quality of care provided by child care centres in the $6 \mathrm{MOH}$ areas of CMC area was mediocre.

- Quality was significantly higher in preschools with the desired child: staff ratio $\left(\mathrm{X}^{2}=13.028\right.$, df- $1, \mathrm{p}<0.001$ )

- Whilst $90 \%$ of centres had teachers with preschool training, which is the recommendation of preschool statute, this was not associated with better quality care $\left(\mathrm{X}^{2}=\right.$ 3.047, df-2, p 0.218)

- Preschools with monthly cost of Rs. 500.001500.00 and $>1500.00$ provided better quality care $\left(X^{2}=7.92\right.$, df-2, p 0.019)

\section{Acknowledgements}

We thank Dr Dulani Samaranayake, Lecturer in Community Medicine, Faculty of Medicine, Colombo, for the statistical analysis of data. 


\section{References}

1. Barnett W, Steven. Long-term effects of early childhood programs on cognitive and school outcomes. Future of Children 1995; 5(3):2550.

http://dx.doi.org/10.2307/1602366

2. Peisner-Feinberg E, Burchinal M. Relations between preschool children's child care experiences and concurrent development. The Cost, Quality and Outcomes Study. MerrillPalmer Quarterly1997; 43(3): 451-77.

3. Harms T, Clifford R, Cryer D. Early Childhood Environment Rating ScaleRevised. New York: Columbia University Teachers College Press.1998.

4. Classroom Assessment Scoring System ${ }^{\mathrm{TM}}$. Available from;

http://curry.virginia.edu/research/centers/castl/ class

5. Lwanga SK, Lemeshow S. Sample size determination in health studies: A practical manual. Geneva: World Health Organization; 1991

6. Fiene, R. National Resource Centre for Health and Safety in Child Care: Key indicator research brief Capital Area Early Childhood Training Institute, Pennsylvania State University.2001 Jan: 1-92.
7. National Institute of Child Health and Human Development (NICHD). Characteristics and quality of child care for toddlers and preschoolers. Applied Developmental Science 2000: 4(3): 116-35 http://dx.doi.org/10.1207/S1532480XADS040 $\underline{32}$

8. Nation Institute of Child Health and Human Development Early Child Care Research Network. Structure $>$ process $>$ outcome: Direct and indirect effects of caregiving quality on young children's development. Psychological Science 2002: 13: 199-206. http://dx.doi.org/10.1207/S1532480XADS040 3_2

9. Peisner-Feinberg E. Burchinal, et al .The children of the cost, quality, and outcomes study go to school: Executive summary. Chapel Hill: University of North Carolina 1999 Jun: 1-20

10. Resnic G, Zill N, Westat, Head Start Providing High-Quality Educational Services? "Unpacking" Classroom Processes. 1999 Apr: $1-14$

11. Marshall NL, Creps CL, et al.. Early Care and Education in Massachusetts Public School Preschool Classrooms: Executive Summary. 2002 1-11 